\title{
Transoesophageal Doppler echocardiographic measurement of cardiac output by the mitral annulus method
}

\author{
Hiroyuki Shimamoto, Hiroyuki Kito, Kohei Kawazoe, Tsuyoshi Fujita, Yoriko
} Shimamoto

\begin{abstract}
Objective-To compare cardiac output measured by the transoesophageal Doppler and thermodilution techniques.

Design-Prospective direct comparison of paired measurements by both techniques in each patient.

Setting-Intensive care unit in a cardiovascular centre.

Patients -65 patients after open heart surgery (mean (SD) age 53 (12) years).

Interventions-Cardiac output was measured simultaneously by the transoesophageal Doppler and thermodilution techniques. Cardiac output was measured again after a mechanical intervention or volume loading.

Results-The limits of agreement were -2.53 to $+0.831 \cdot \mathrm{min}^{-1}$ for cardiac output measured by the Doppler and thermodilution techniques. This suggests that the Doppler method alone would not be suitable for clinical use. The second measurement of cardiac output by thermodilution was compared with cardiac output estimated from the first and second Doppler measurements and the first thermodilution measurement. The limits of agreement $(-0.55$ to +0.51 $\left.1 \cdot \min ^{-1}\right)$ were good enough for clinical use.
\end{abstract}

Conclusions-After cardiac output had been measured simultaneously by both the Doppler and thermodilution techniques, subsequent transoesophageal Doppler alone gave a clinically useful measurement of cardiac output.

\section{(Br Heart J 1992;68:510-5)}

The Fick, dye dilution, and thermodilution methods are regarded as the most accurate methods for measuring cardiac output. Quantitative transthoracic Doppler echocardiography is used in many centres to measure cardiac output. ${ }^{1}$ The transthoracic approach is known to be a valid method of measuring flow in the ascending aorta (suprasternal view), flow in the pulmonary artery (parasternal view), ${ }^{2}$ left ventricular outflow (apical view), ${ }^{3}$ and transmitral flow (apical view). ${ }^{3}$

Transoesophageal echocardiography has been used to monitor left ventricular performance ${ }^{4}$ and diagnose myocardial ischaemia. ${ }^{5}$ Transoesophageal systems can be used to obtain pulsed Doppler echocardiographic measurements, which permit determination of flow velocity in a specified lucation over time. Ultrasonic access to the heart from the oesophagus is not restricted by the lungs or ribs and the technique can be used to record blood velocity in patients after open heart surgery.

We used transoesophageal pulsed Doppler echocardiography to measure cardiac output from the transmitral flow velocity and the diameter of the mitral annulus.

\section{Patients and methods}

PATIENTS

We studied 65 patients ( 40 men and 25 women, aged (mean (SD)) 53 (12) years). Thirty seven patients underwent coronary artery bypass grafting, 15 aortic valve replacement, 12 reconstruction of the ascending aorta and/or aortic arch by composite valve graft or graft only, and one tricuspid valvuloplasty. All patients were postoperatively ventilated in the intensive care unit. Patients were sedated during ventilation. All patients were studied $1-48 \mathrm{~h}$ after operation in a stable haemodynamic condition. None of the patients showed clinical, echocardiographic, or Doppler evidence of mitral stenosis. None had mitral regurgitation of $>1+$ on preoperative left ventriculography (Sellers criteria $)^{6}$ or on pre and post operative pulsed Doppler echocardiography. ${ }^{7}$ In all but the one who underwent tricuspid valvuloplasty the maximal distance from the tricuspid orifice reached by the regurgitant signals was less than $1.5 \mathrm{~cm}(+1 \text { tricuspid regurgitation })^{8}$ on pre and post operative transthoracic pulsed Doppler echocardiography. In one patient who had had severe tricuspid regurgitation and had had tricuspid valvuloplasty, postoperative transoesophageal Doppler echocardiography showed trivial tricuspid regurgitation, and transthoracic echocardiography performed 14 days after the operation confirmed +1 tricuspid regurgitation. All patients were in normal sinus rhythm. After an explanation of the nature and the purpose of the study they gave their informed consent.

Cardiovascular Surgery, National Centre, Fujishiroda H Shimamoto K Kawazoe

Department of

Y Shimamoto

Correspondence to:

Japan. April 1992.
} 
CARDIAC OUTPUT DETERMINED BY TRANSOESOPHAGEAL DOPPLER ECHOCARDIOGRAPHY

All of the transoesophageal echocardiographic studies were performed a few minutes before cardiac output was measured by the thermodilution technique. A 3.75 $\mathrm{MHz}$ transoesophageal echocardiographic probe (Machida, ESB-37SR, Japan) was inserted into the oesophagus. Images were obtained with a directional pulsed Doppler flowmeter incorporated in a wide angle phased array echograph (Toshiba Sonolayergraph 65A and Toshiba SDS21A, Tokyo, Japan). This system uses a fast Fourier transformation by a spectral analyser system which displays the different red blood cell velocities within the cardiac chambers. The cut-off frequency of the highpass filter was set to $400 \mathrm{~Hz}$. The pulse repetition rate was 4 or $6 \mathrm{kHz}$. The depth of sample volume was about $3 \mathrm{~mm}$. The smallest feasible angle was maintained during all Doppler measurements. Correction for the angle of incidence was made in all measurements. The angle of incidence was less than $20^{\circ}$ in 27 patients and it ranged from $20^{\circ}$ to $35^{\circ}$ in 38 . The Doppler signals were displayed simultaneously with the electrocardiogram and $M$ mode echocardiogram by a strip chart recorder (Toshiba LSR20A) and a paper speed of 50 $\mathrm{mm} / \mathrm{s}$. Flow velocity components toward and away from the transducer were displayed above and below the baseline, respectively.

The transducer was manipulated to obtain a four chamber view with the sample volume at the centre of the mitral ring where the velocity was fastest. Colour flow imaging was used to keep the beam parallel with the transmitral flow. Mitral inflow velocity was recorded over several cardiac cycles. We used the machine's computer to obtain an integrated angle correction for the Doppler technique and then we used planimetry of the resulting mitral flow velocity curve to obtain the velocity-time integral for mitral flow (figure 1). Five beats were averaged for each determination.
The diameter of the mitral valve annulus was measured at the time of peak rapid filling flow velocity (fig 1). Measurements from a minimum of five cardiac cycles were averaged and the cross section area of the annulus was derived as $\pi \times r^{2}$, where $r$ is half of the diameter of the annulus. This method assumes that the mitral annulus is circular and the cross sectional area is constant throughout diastole. Cardiac output was calculated as the product of the velocity-time integral for mitral diastolic flow and the cross sectional area of the mitral annulus (which gave the stroke volume) multiplied by heart rate. We called cardiac output determined by this Doppler technique the Doppler cardiac output.

A second independent observer repeated the Doppler determination of cardiac output in 15 patients to test for interobserver differences. Cardiac output measured by the Doppler technique was repeated a few minutes later in 15 patients to test for intraobserver differences. Inter and intra observer differences were determined as the difference between the two observations divided by the mean of the two observations.

\section{CARDIAC OUTPUT MEASURED BY THE}

THERMODILUTION TECHNIQUE

A Swan-Ganz thermodilution catheter (American Edwards Laboratory) was inserted into the pulmonary artery. Cardiac output was determined by Swan-Ganz catheter with $5 \%$ glucose in water at $0^{\circ} \mathrm{C}$ as the indicator. We used a bedside thermodilution cardiac output computer (American Edwards Labratory, COC-9520-A) for the calculations. We called cardiac output determined by thermodilution the thermal cardiac output. Five measurements of thermal cardiac output were obtained. The high and low values were discarded and a mean of the three remaining values was calculated if the variability of these determinations did not exceed $15 \%$. Because of considerable variability in 12 patients, five new measurements were made and the procedure
Figure 1 (A)

Measurements of indices from mitral flow pattern. Transoesophageal four chamber view showing sampling volume ( $S V)$ for Doppler measurement (white arrow) in the centre of the mitral ring and the diameter $(D)$ of the mitral valve annulus. (B) Doppler

echocardiographic flow signal recorded at $S V$. Doppler flow signals indicate the instantaneous mean mitral flow velocity and are used to measure the mitral flow integral. $L V$, left ventricle; $L A$, left atrium; ECG, electrocardiogram TOW ARD, flow components toward the transducer; $A W A Y$, flow components away from the transducer.
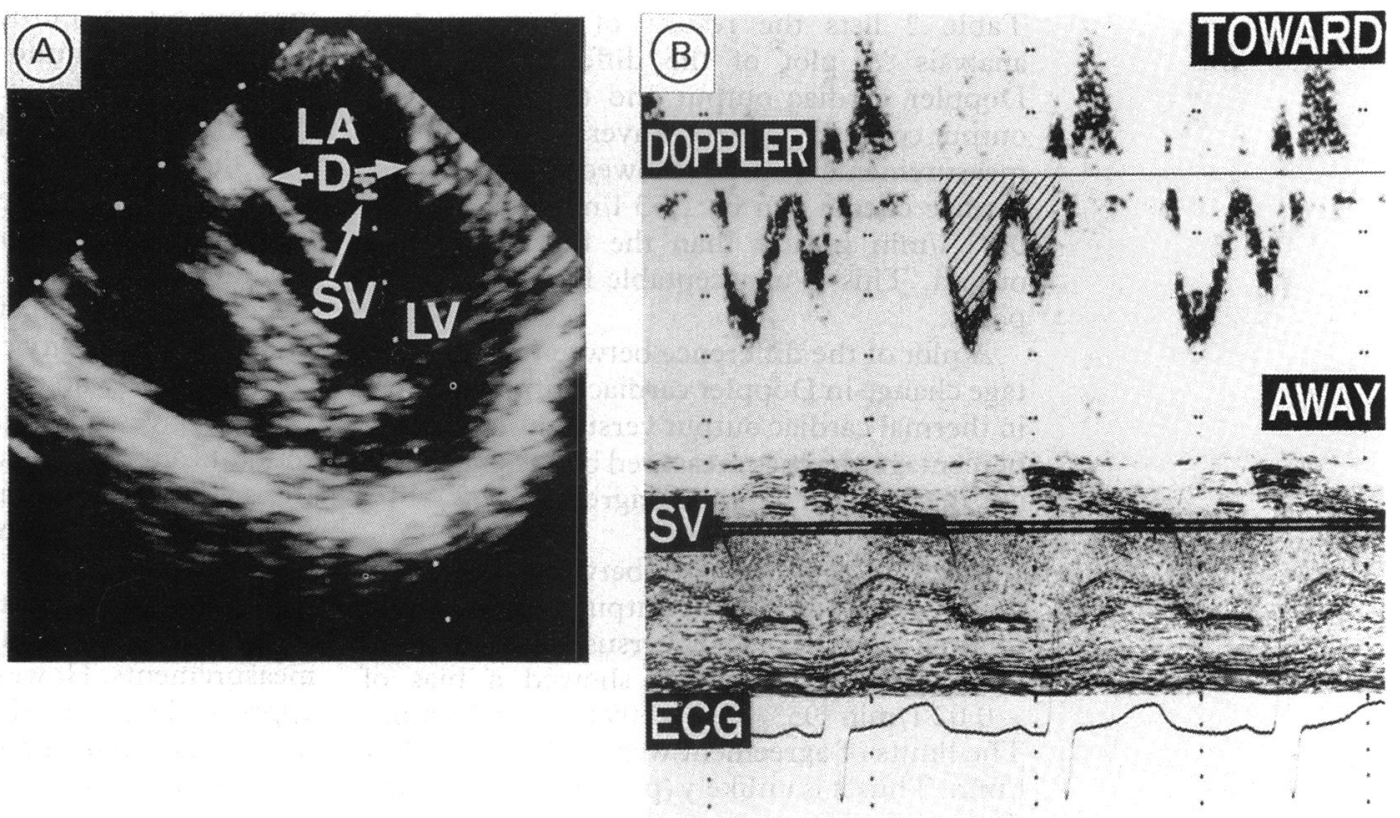
was repeated. To test inter and intraobserver variability, measurements of thermal cardiac output were repeated in 15 and 20 patients respectively. Inter and intraobserver differences were calculated as the difference between the two observations divided by the mean value of the two observations.

ESTIMATION OF THE SECOND MEASUREMENT OF THERMAL CARDIAC OUTPUT FROM THE FIRST AND SECOND MEASUREMENTS OF DOPPLER CARDIAC OUTPUT AND THE FIRST MEASUREMENT OF THERMAL CARDIAC OUTPUT

We measured changes in thermal cardiac output and Doppler cardiac output induced by fluid infusions or associated with positive end expiratory pressure or intraaortic balloon pumping.

Percentage changes in Doppler cardiac output were compared with those in thermal cardiac output. We also estimated what the second measurement (after intervention) of thermal cardiac output was from the first thermal cardiac output, first Doppler cardiac output, and the second Doppler cardiac output:

Second thermal Doppler cardiac output $(1 / \mathrm{min})=$

first thermal cardiac output $\times \frac{\text { second Doppler cardiac output }}{\text { first Doppler cardiac output }}$

We assessed whether the second thermal Doppler cardiac output was clinically valuable.

STATISTICAL ANALYSIS

Data are expressed as mean (SD). Data were analysed by the method of Bland and Altman.

\section{Results}

Table 1 gives the measurements in individual patients. No patients were excluded from the study because of poor quality echocardiographic or Doppler data.

ASSESSMENT OF THERMAL CARDIAC OUTPUT AND DOPPLER CARDIAC OUTPUT BY THE METHOD OF BLAND AND ALTMAN

Table 2 lists the results of this statistical analysis. A plot of the difference between Doppler cardiac output and thermal cardiac output compared with the average of these two measurements (fig 2) showed that Doppler cardiac output can be $2.53 \mathrm{l} / \mathrm{min}$ less than or $0.83 \mathrm{l} / \mathrm{min}$ greater than the thermal cardiac output. This is unacceptable for clinical purposes.

A plot of the difference between the percentage change in Doppler cardiac output and that in thermal cardiac output versus the average of percentage changes measured by the two methods (fig 3) showed limits of agreement of $-14 \cdot 7$ to $+13 \cdot 4 \%$

A plot of the difference between the second thermal Doppler cardiac output and the second thermal cardiac output versus the average of these two measurements showed a bias of $-0.021 / \mathrm{min}(95 \% \mathrm{CI}-0.09$ to $+0.05 \mathrm{l} / \mathrm{min})$. The limits of agreement were -0.55 to +0.51 $1 /$ min. Thus it is unlikely $(p<0.05$ ) that second thermal cardiac output and second thermal
Doppler cardiac output in the same individual would differ by more than $0.55 \mathrm{l} / \mathrm{min}$.

\section{INTRA AND INTER OBSERVER VARIABILITY}

Thermal cardiac output

The percentage differences were $4.3(2.5) \%$ for duplicate measurements by one observer and $5 \cdot 1(3 \cdot 3) \%$ for two independent observers.

\section{Doppler cardiac output}

The percentage differences were $4 \cdot 1$ (3.8) $\%$ for duplicate measurements by one observer and $5 \cdot 7(4 \cdot 3) \%$ for the two independent observers.

\section{Discussion}

Transoesophageal echocardiography has become established as a valuable method for postoperative monitoring of cardiac structure and left ventricular function in patients undergoing open-heart surgery. Transthoracic echocardiography often does not give good enough images in such patients. Transoesophageal echocardiography is facilitated in patients in the intensive care unit because they are sedated during ventilation. Furthermore, the technique gives an excellent view of the mitral apparatus and an optimal angle between the sound beam and transmitral flow. The thermodilution technique is the method most frequently used to measure cardiac output because it is simple to do with good precision. ${ }^{10}$ Because prolonged maintenance of intraventricular catheters predisposes to the development of bacteraemia and endocarditis, the thermodilution catheter should be removed as soon as possible.

The objective of this study was to validate the use of the Doppler technique described as a reliable means of determining postoperative cardiac output. We found that the Doppler method on its own was not accurate enough for one off measurements of cardiac output. But once both thermal cardiac output and Doppler cardiac output had been measured simultaneously in a patient, subsequent transoesophageal Doppler measurement could be used to measure cardiac output without the need for a further thermodilution measurement.

There may be several reasons for the differences between Doppler cardiac output and thermal cardiac output. The angle of incidence between the sound beam and transmitral flow is an important determinant of the accuracy of Doppler measurements of blood velocity. Angles of incidence of $\leqslant 20^{\circ}$ have little influence on velocity calculations because their cosine is nearly unity. The transthoracic apical window gives an angle of $\leqslant 20^{\circ}$ between the sound beam and transmitral flow, whereas the transoesophageal approach limits the number of views that can be obtained and this results in an angle more than $20^{\circ}$ between the sound beam and the transmitral flow. In our study we corrected for the angle of incidence in all measurements. However, there may still be an appreciable angle of incidence between the ultrasound beam and the real vectorial force of transmitral flow. The transoesophageal four chamber view is similar to the apical image 
Table 1 Data from Doppler echocardiographic and thermodilution techniques

\begin{tabular}{|c|c|c|c|c|c|c|c|c|c|}
\hline \multirow[b]{2}{*}{ Patient No } & \multirow[b]{2}{*}{$\operatorname{Age}(y r)$} & \multirow[b]{2}{*}{ Sex } & \multirow[b]{2}{*}{ Operation } & \multirow{2}{*}{$\begin{array}{l}\text { Doppler } \\
\text { cardiac } \\
\text { output }\end{array}$} & \multicolumn{5}{|c|}{ Thermal cardiac output } \\
\hline & & & & & \#1 & $\$ 2$ & $\# 3$ & Mean & $S D$ \\
\hline 1 & 68 & $\mathbf{M}$ & CABG & 3.01 & $2 \cdot 61$ & $2 \cdot 44$ & $2 \cdot 49$ & 2.51 & 0.07 \\
\hline 2 & 62 & $\mathrm{~F}$ & CABG & $2 \cdot 44$ & $2 \cdot 79$ & $2 \cdot 85$ & 3.00 & $2 \cdot 88$ & 0.09 \\
\hline 3 & 66 & $\mathrm{~F}$ & CABG & 2.82 & 3.82 & 3.95 & $4 \cdot 11$ & 3.96 & 0.12 \\
\hline 4 & 57 & $\mathbf{M}$ & CABG & 1.88 & $2 \cdot 43$ & 2.56 & 2.55 & 2.51 & 0.06 \\
\hline 5 & 44 & $\mathbf{M}$ & CABG & 3.05 & $4 \cdot 26$ & $3 \cdot 88$ & 3.92 & $4 \cdot 02$ & 0.17 \\
\hline 6 & 54 & $F$ & CABG & $2 \cdot 40$ & 3.88 & 3.93 & 4.09 & 3.97 & 0.09 \\
\hline 7 & 55 & $\mathbf{M}$ & $\mathrm{CABG}$ & $2 \cdot 60$ & 2.85 & 3.08 & 3.11 & 3.01 & 0.12 \\
\hline 8 & 68 & $\mathbf{M}$ & CABG & 3.53 & 2.69 & $2 \cdot 83$ & 2.92 & $2 \cdot 81$ & 0.09 \\
\hline 9 & 67 & $M$ & CABG & $5 \cdot 40$ & $5 \cdot 71$ & 5.75 & 5.85 & $5 \cdot 77$ & 0.06 \\
\hline 10 & 51 & $\mathbf{M}$ & CABG & $2 \cdot 74$ & $3 \cdot 78$ & 3.61 & $3 \cdot 47$ & 3.62 & 0.13 \\
\hline 11 & 55 & $\mathbf{F}$ & CABG & 2.41 & $2 \cdot 17$ & 2.02 & 2.05 & 2.08 & 0.06 \\
\hline 12 & 67 & $\mathbf{M}$ & CABG & 4.92 & 4.95 & 4.96 & 5.21 & 5.04 & 0.12 \\
\hline 13 & 49 & $F$ & CABG & 1.94 & 3.64 & 3.51 & 3.56 & 3.57 & 0.05 \\
\hline 14 & 52 & M & CABG & $2 \cdot 87$ & 4.45 & $4 \cdot 39$ & 4.61 & $4 \cdot 48$ & 0.09 \\
\hline 15 & 62 & M & CABG & 1.75 & 1.71 & 1.66 & 1.66 & 1.68 & 0.02 \\
\hline 16 & 54 & M & CABG & 2.83 & 5.39 & 5.22 & $5 \cdot 11$ & $5 \cdot 24$ & 0.12 \\
\hline 17 & 53 & M & CABG & $2 \cdot 21$ & 2.48 & 2.71 & 2.55 & 2.58 & $0 \cdot 10$ \\
\hline 18 & 63 & $\mathbf{F}$ & CABG & 2.51 & $2 \cdot 47$ & $2 \cdot 61$ & 2.61 & 2.56 & 0.07 \\
\hline 19 & 69 & $F$ & CABG & 2.65 & $2 \cdot 88$ & 2.84 & 2.95 & 2.89 & 0.05 \\
\hline 20 & 48 & $\mathbf{M}$ & CABG & 2.45 & 3.06 & 2.95 & 2.81 & 2.94 & $0 \cdot 10$ \\
\hline 21 & 56 & M & CABG & 2.26 & $4 \cdot 31$ & $4 \cdot 33$ & 4.09 & $4 \cdot 24$ & 0.11 \\
\hline 22 & 54 & $\mathbf{M}$ & CABG & 2.09 & $4 \cdot 31$ & $4 \cdot 29$ & $4 \cdot 46$ & $4 \cdot 35$ & 0.08 \\
\hline 23 & 49 & $\mathbf{F}$ & CABG & 2.57 & 4.22 & $4 \cdot 31$ & 3.99 & $4 \cdot 17$ & 0.13 \\
\hline 24 & 59 & $\mathbf{F}$ & CABG & 1.53 & 3.65 & 3.51 & 3.49 & 3.55 & 0.07 \\
\hline 25 & 60 & M & CABG & 4.32 & $5 \cdot 10$ & 5.33 & 4.95 & 5.13 & 0.16 \\
\hline 26 & 65 & $\mathbf{F}$ & CABG & $2 \cdot 41$ & $5 \cdot 11$ & 5.02 & 5.01 & 5.05 & 0.04 \\
\hline 27 & 53 & M & CABG & $2 \cdot 82$ & 3.91 & 3.84 & 3.76 & 3.84 & 0.06 \\
\hline 28 & 62 & M & CABG & 1.47 & 3.95 & 3.77 & 3.78 & 3.83 & 0.08 \\
\hline 29 & 51 & M & CABG & 2.03 & 3.91 & 4.02 & 4.05 & 3.99 & 0.06 \\
\hline 30 & 47 & $F$ & CABG & $2 \cdot 70$ & 3.44 & 3.38 & 3.52 & 3.45 & 0.06 \\
\hline 31 & 58 & $F$ & CABG & 3.34 & 3.79 & 3.97 & 3.91 & 3.89 & 0.07 \\
\hline 32 & 53 & M & CABG & 2.64 & 4.21 & $4 \cdot 29$ & $4 \cdot 19$ & $4 \cdot 23$ & 0.04 \\
\hline 33 & 66 & M & CABG & $2 \cdot 19$ & 3.65 & 3.78 & 3.95 & 3.79 & 0.12 \\
\hline 34 & 61 & $\mathbf{M}$ & CABG & $2 \cdot 34$ & $3 \cdot 15$ & 3.04 & $2 \cdot 88$ & 3.02 & 0.11 \\
\hline 35 & 55 & $\mathbf{M}$ & CABG & 1.87 & $2 \cdot 45$ & 2.54 & $2 \cdot 42$ & $2 \cdot 47$ & 0.05 \\
\hline 36 & 57 & $\mathbf{F}$ & CABG & 2.54 & 3.41 & 3.36 & 3.59 & 3.45 & 0.10 \\
\hline 37 & 49 & $\mathbf{F}$ & CABG & 1.96 & $2 \cdot 01$ & 2.09 & 2.01 & 2.04 & 0.04 \\
\hline 38 & 20 & M & AVR & 3.22 & $4 \cdot 37$ & 4.51 & 4.50 & $4 \cdot 46$ & 0.06 \\
\hline 39 & 55 & M & AVR & 3.01 & $2 \cdot 67$ & $2 \cdot 77$ & $2 \cdot 81$ & 2.75 & 0.06 \\
\hline 40 & 34 & $\mathrm{~F}$ & AVR & 5.40 & 5.02 & 4.54 & $4 \cdot 76$ & $4 \cdot 77$ & 0.20 \\
\hline 41 & 51 & F & AVR & 3.29 & 3.75 & 3.85 & 4.08 & 3.89 & 0.14 \\
\hline 42 & 46 & M & AVR & $3 \cdot 20$ & 5.02 & 5.09 & 5.01 & 5.04 & 0.04 \\
\hline 43 & 33 & M & AVR & 3.06 & 2.65 & 2.65 & 2.76 & 2.69 & 0.05 \\
\hline 44 & 61 & $\mathbf{M}$ & AVR & $3 \cdot 25$ & 5.37 & 5.15 & $5 \cdot 17$ & $5 \cdot 23$ & 0.10 \\
\hline 45 & 27 & $\mathbf{M}$ & AVR & 3.36 & 4.45 & 4.36 & 4.05 & $4 \cdot 29$ & 0.17 \\
\hline 46 & 55 & F & AVR & $3 \cdot 18$ & 3.31 & 3.39 & 3.47 & 3.39 & 0.07 \\
\hline 47 & 39 & $\mathbf{M}$ & AVR & $3 \cdot 24$ & $4 \cdot 19$ & 4.06 & 3.85 & 4.03 & 0.14 \\
\hline 48 & 40 & $\mathbf{M}$ & AVR & $4 \cdot 48$ & $5 \cdot 72$ & $5 \cdot 66$ & $5 \cdot 67$ & $5 \cdot 68$ & 0.03 \\
\hline 49 & 31 & $\mathbf{M}$ & AVR & 3.80 & $4 \cdot 78$ & $4 \cdot 72$ & $4 \cdot 71$ & $4 \cdot 74$ & 0.03 \\
\hline 50 & 29 & $\mathbf{F}$ & AVR & 3.34 & 2.38 & 2.28 & $2 \cdot 32$ & 2.33 & 0.04 \\
\hline 51 & 37 & $\mathbf{F}$ & AVR & 3.20 & 3.91 & 3.82 & 3.98 & 3.90 & 0.07 \\
\hline 52 & 52 & $\mathbf{F}$ & AVR & $4 \cdot 37$ & 6.05 & $6 \cdot 16$ & 5.88 & 6.03 & 0.12 \\
\hline 53 & 71 & $\mathbf{M}$ & ARO & 4.77 & 5.59 & 5.78 & 5.41 & 5.59 & 0.15 \\
\hline 54 & 68 & $\mathbf{M}$ & ARO & 2.99 & $2 \cdot 26$ & 2.24 & 2.35 & $2 \cdot 28$ & 0.05 \\
\hline 55 & 50 & $\mathrm{~F}$ & ARO & $2 \cdot 27$ & 3.20 & 3.15 & 3.08 & $3 \cdot 14$ & 0.05 \\
\hline 56 & 61 & $\mathbf{F}$ & ARO & 1.82 & 3.11 & 3.29 & 3.35 & 3.25 & $0 \cdot 10$ \\
\hline 57 & 32 & $\mathbf{M}$ & ARO & 3.04 & 3.76 & 3.55 & 3.71 & 3.67 & 0.09 \\
\hline 58 & 50 & $\mathrm{M}$ & ARO & 2.58 & 4.85 & $5 \cdot 12$ & 4.89 & 4.95 & 0.12 \\
\hline 59 & 43 & $\mathbf{F}$ & ARO & $2 \cdot 20$ & 2.79 & 2.76 & 2.64 & 2.73 & 0.06 \\
\hline 60 & 75 & $\mathrm{~F}$ & ARO & 1.62 & $2 \cdot 21$ & 2.40 & 2.34 & $2 \cdot 32$ & 0.08 \\
\hline 61 & 63 & $\mathbf{M}$ & ARO & 3.55 & 4.44 & $4 \cdot 58$ & $4 \cdot 49$ & 4.50 & 0.06 \\
\hline 62 & 52 & $\mathbf{M}$ & ARO & $2 \cdot 20$ & 2.77 & $2 \cdot 60$ & 2.57 & 2.65 & 0.09 \\
\hline 63 & 38 & $\mathrm{~F}$ & ARO & $2 \cdot 49$ & 2.39 & $2 \cdot 36$ & $2 \cdot 18$ & $2 \cdot 31$ & 0.09 \\
\hline 64 & 55 & $\mathbf{M}$ & ARO & $3 \cdot 20$ & $4 \cdot 15$ & 4.03 & 3.87 & 4.02 & 0.11 \\
\hline 65 & 56 & $\mathbf{M}$ & TVP & 4.03 & $5 \cdot 60$ & $5 \cdot 67$ & $5 \cdot 64$ & $5 \cdot 64$ & 0.03 \\
\hline
\end{tabular}

Doppler cardiac output is the cardiac output determined by the Doppler technique $\left(1 \cdot \mathrm{min}^{-1}\right)$; thermal cardiac output is cardiac output determined by the thermodilution technique $\left(1 \cdot \mathrm{min}^{-1}\right)$; CABG, coronary artery bypass grafting; AVR, aortic valve replacement; ARO, aortic reconstructive operation; ascending aorta and/or aortic arch reconstruction by composite valve graft or graft only; TVP, tricuspid valvuloplasty.

Table 2 Statistical analysis by method of Bland and Altman

\begin{tabular}{|c|c|c|c|}
\hline & $\begin{array}{l}\text { Cardiac output }\left(l \cdot \min ^{-1}\right) \\
\text { Doppler cardiac output } v \\
\text { thermal cardiac output }\end{array}$ & $\begin{array}{l}\% \text { change in cardiac output } \\
\text { by Doppler v thermal }\end{array}$ & $\begin{array}{l}\text { Cardiac output }\left(l \cdot \min ^{-1}\right) \\
\text { second thermal Doppler cardiac output } \\
v \text { second thermal cardiac output }\end{array}$ \\
\hline \multirow{3}{*}{$\begin{array}{l}\text { Bias } \\
\text { Limits of agreement } \\
95 \% \text { confidence interval for bias } \\
95 \% \text { confidence interval for upper part } \\
\text { of agreement } \\
95 \% \text { confidence interval for lower } \\
\text { part of agreement }\end{array}$} & $\begin{array}{l}-0.85 \\
-2.53 \text { to }+0.83 \\
-1.05 \text { to }-0.65\end{array}$ & $\begin{array}{l}-0 \cdot 6 \\
-14 \cdot 7 \text { to }+13 \cdot 4 \\
-2 \cdot 3 \text { to }+1 \cdot 1\end{array}$ & $\begin{array}{l}-0.02 \\
-0.55 \text { to }+0.51 \\
-0.09 \text { to }+0.05\end{array}$ \\
\hline & $+0 \cdot 47$ to $+1 \cdot 19$ & $+10 \cdot 4$ to $+16 \cdot 4$ & +0.40 to +0.62 \\
\hline & -2.89 to -2.17 & -17.7 to -11.7 & -0.66 to -0.44 \\
\hline
\end{tabular}

Doppler cardiac output is the cardiac output determined by the Doppler technique. Thermal cardiac output is the cardiac output determined by the thermodilution technique. The second thermal cardiac output is the second measurement of thermal cardiac output after intervention. The second thermal Doppler cardiac output is the estimated second measurement of thermal cardiac output that was derived from both the first and second Doppler measurements and the first thermodilution measurement. 


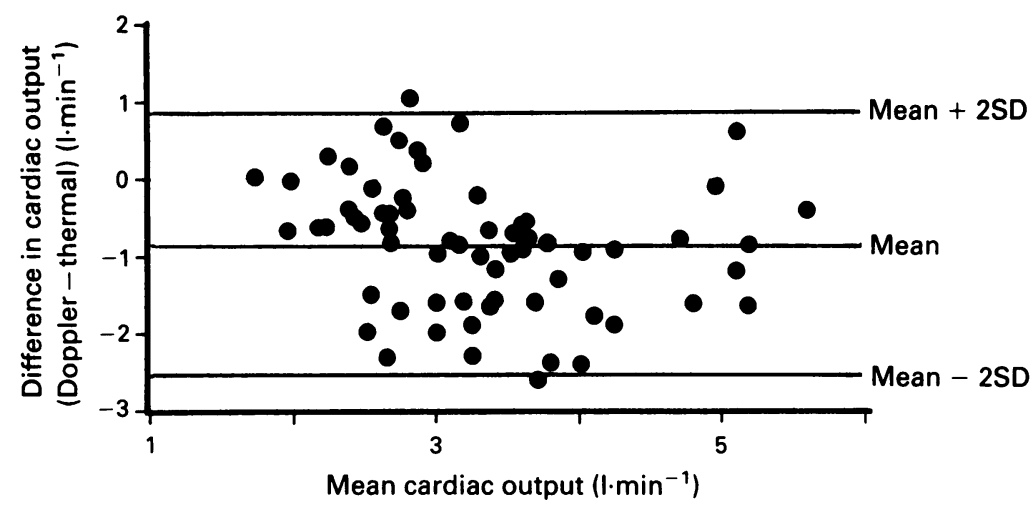

Figure 2 Difference between Doppler cardiac output and thermal cardiac output plotted against the mean of these two measurements. Doppler cardiac output is the cardiac output measured by the Doppler echocardiographic technique. Thermal cardiac output is the cardiac output measured by the thermodilution technique.

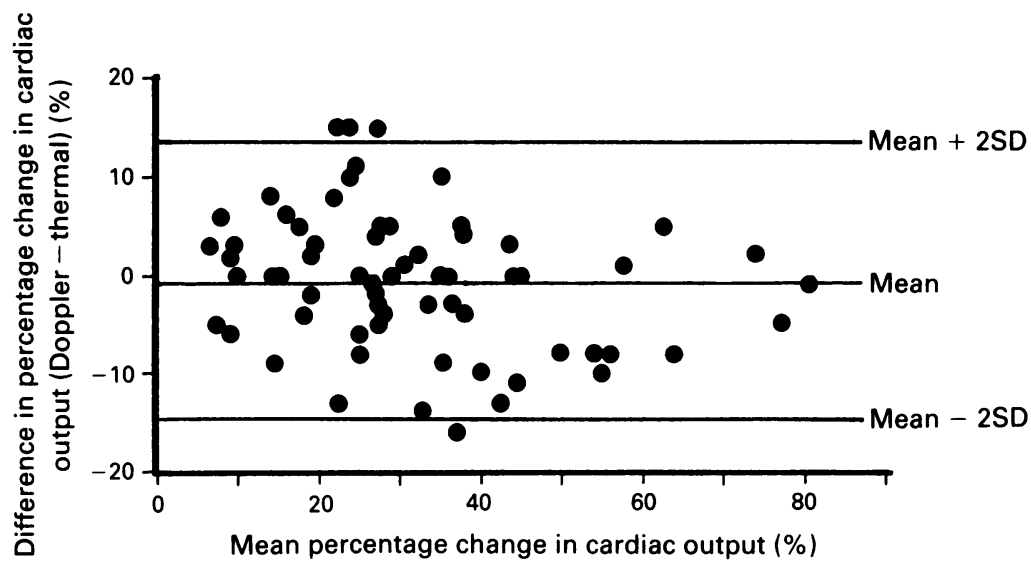

Figure 3 Difference between the percentage change in the Doppler cardiac output and that in the thermal cardiac output plotted against the mean of the percentage changes measured by the two methods.

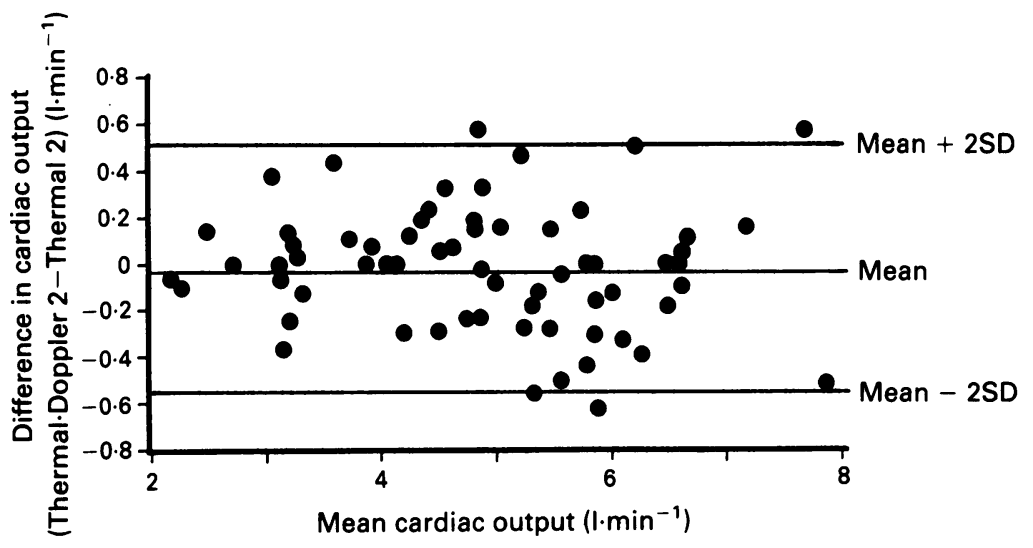

Figure 4 Difference between the second thermal Doppler cardiac output (thermal Doppler 2) and second thermal cardiac output (thermal 2) plotted against the mean of these two measurements. The second thermal cardiac output is the second measurement of cardiac output determined by thermodilution technique, the second thermal Doppler cardiac output is the estimated second measurement of thermal cardiac output, which was derived from both the first and second Doppler measurements and the first thermodilution measurement.
Another factor that may increase the difference between thermal cardiac output and Doppler cardiac output is the use of a single mitral annular diameter to estimate the cross sectional area of the annulus. Transthoracic echocardiography can be used to determine the cross sectional area of the annulus if it is assumed that the mitral annulus is elliptical with two orthogonal annular diameters ${ }^{312}$ or circular with a single diameter. ${ }^{3}$ Because transoesophageal cross sectional echocardiography mainly images horizontal sections it cannot measure two orthogonal annular diameters. Thus at present the only practical alternative is to calculate the area from a single diameter measurement. When Ormiston et al measured the mitral annulus in healthy controls by cross sectional echocardiography they found that the mitral annulus was nearly circular. ${ }^{13}$ Lewis et al reported that the mitral annular area derived from two orthogonal diameters was nearly identical with that derived from one diameter alone. ${ }^{3}$ Therefore we assumed that the mitral annulus is circular and used the single measurement method.

Axial resolution in phased array cross sectional echocardiographs is precise, whereas lateral resolution remains less certain. From the four chamber view, the transoesophageal ultrasound beam is roughly perpendicular to the mitral annulus and this may be an additional factor in the large difference between the two measurements.

In this study, we assumed that the cross sectional area of the mitral annulus was constant throughout diastole. The size of the mitral annulus was reported to change during the cardiac cycle. Ormiston $e t a l^{13}$ found that it increased gradually by $12 \%$ from early diastole to end diastole. This change represents a small change in diameter because the annular diameter is related to the square root of area. Thus we measured the diameter of the mitral annulus at peak rapid filling flow velocity in our study.

Tricuspid or mitral regurgitation can influence measurements of cardiac output by both the thermodilution and Doppler techniques. Thermal cardiac output basically provides an assessment of cardiac output from the right side of the heart. Patients who have considerable tricuspid regurgitation cannot have their forward left heart output accurately estimated by the thermodilution technique, ${ }^{14}$ and in those with mitral regurgitation the Doppler cardiac output obtained from transmitral flow was an overestimate. ${ }^{3}$ Therefore, ideally, these techniques for measuring cardiac output should be applied in patients without valve regurgitation. This is almost impossible because tricuspid reurgitation was detected in $15-64 \%$ and mitral regurgitation in $38-43 \%$ of healthy people aged from 20 to 49 years. ${ }^{15}$ Also both tricuspid and mitral regurgitation as detected by pulsed Doppler echocardiography increase with age in apparently healthy people aged $\geqslant 60$ years. ${ }^{16}$ Second, the presence of the thermodilution catheter itself causes some tricuspid regurgitation which might interfere with the thermodilution technique. Fortunnot be determined with certainty, we di correct for an estimated angle between the imaging plane and the long axis of the left ventricle.

obtained with surface echocardiograms, but it does not include the true left ventricular apex. Thus the cross sectional imaging plane may not ventricle. However, because the precise angle 
ately, the severity of both tricuspid and mitral regurgitation was less than +1 in all our subjects: any error related to valve regurgitation would affect both measurements and in any case is believed to be minimal.

Comparison of precordial and transoesophageal studies would have been helpful but was not possible. The poor sensitivity and image quality of transthoracic echocardiography, especially in patients after open heart surgery, interfere with measurements of Doppler cardiac output. Because it is unacceptable to perform transoesophageal Doppler measurements postoperatively in patients who have not been fully sedated or who have satisfactory images from the transthoracic technique we did not compare these two Doppler measurements.

We found that transoesophageal Doppler measurements of cardiac output from transmitral flow alone may be unreliable. However, once both thermal cardiac output and Doppler cardiac output are determined simultaneously, subsequent cardiac output can be estimated from a single measurement of transoesophageal Doppler cardiac output. This new method extends the applicability of measuring cardiac output by transoesophageal echocardiography to patients in sinus rhythm after cardiac surgery.

1 Huntsman LL, Stewart DK, Barnes SR, Franklin SB, Colocousis JS, Hessel EA. Noninvasive Doppler determination of cardiac output in man-clinical validation. Circulation 1983;67:593-602.

2 Valdes-Cruz LM, Horowitz S, Mesel E, Sahn DJ, Fisher DC, Larson D. A pulsed Doppler echocardiographic method for calculating pulmonary and systemic blood flow in atrial level shunts-validation studies in animal and initial human experience. Circulation 1984;69:80-6.

3 Lewis JF, Kuo LC, Nelson JG, Limacher MC, Quinones
MA. Pulsed Doppler echocardiographic determination of stroke volume and cardiac output-clinical validation of two new methods using the apical window. Circulation 1984;70:425-31.

4 Matsumoto M, Oka Y, Strom J, Frishman W, Kadish A Becker RM, Frater RWM, Sonnenblick EH. Application of transesophageal echocardiography to continuous intraoperative monitoring of left ventricular performance. Am J Cardiol 1980;46:95-105.

5 Smith JS, Cahalan MK, Benefiel DJ, Byrd BF, Lurz FW, Shapiro WA; Roizen MF, Bouchard A, Schiller NB. Intraoperative detection of myocardial ischemia in high-risk patients-electrocardiography versus twodimensional transesophageal echocardiography. Circulation 1985;72:1015-21.

6 Sellers. RD, Levy MJ, Amplatz K, Lillehei CW. Left retrograde cardiac-angiography in acquired cardiac disretrograde Am J Cardiol 1964;14:437-47.

7 Ohwa M, Sakakibara H, Miyatake K, Okamoto M, Kinoshita N, Ueda E, Funahashi T, Nakasone I, Nimura Y. Mhita $N$, Ueda E, Funahashi $T$, Nakasone 1 , Nimura $Y$. Mitral regurgitation-detection and quantitative evaluation by two-dimensional Dop

8 Miyatake K, Okamoto M, Kinoshita N, Ohta M, Kozuka T, Sakakibara H, Nimura Y. Evaluation of tricuspid regurgitation by pulsed Doppler and two-dimensional echocardiography. Circulation 1982;66:777-84.

9 Bland JM, Altman DG. Statistical methods for assessing agreement between two methods of clinical measurement. Lancet 1986;i:307-10.

10 Fischer AP, Benis AM, Jurado RA, Seely E, Teirstein P, Litwak RS. Analysis of errors in measurement of cardiac output by simultaneous dye and thermal dilution in cardiothoracic surgical patients. Cardiovasc Res 1978;12: cardioth

11 Schlüter M, Hinrichs A, Thier W, Kremer P, Schröder S, Cahalan MK, Hanrath P, Siglow V. Transesophageal two-dimensional echocardiography-comparison of ultrasonic and anatomic sections. Am J Cardiol 1984; 53:1173-8.

12 Goldberg SJ, Dickinson DF, Wilson N. Evaluation of an elliptical area technique for calculating mitral blood flow by Doppler echocardiography. Br Heart J 1985;54:68-75.

13 Ormiston JA, Shah PM, Tei C, Wong M. Size and motion of the mitral valve annulus in man-a two dimensional echocardiographic method and findings in normal subjects. Circulation 1981;64:113-20.

14 Ferguson DW, Abboud FM. The pathophysiology, recognition, and management of shock. In: Hurst JW, Schlant 1990;442-61.

15 Yoshida K, Yoshikawa J, Shakudo M, Akasaka T, Jyo Y, Takao S, Shiratori K, Koizumi K, Okumachi F, Kato H, Fukaya T. Color Doppler evaluation of valvular regurgitation in normal subjects. Circulation 1988;78:840-7.

16 Akasaka T, Yoshikawa J, Yoshida K, Okumachi F, Koizumi K, Shiratori K, Takao S, Shakudo M, Kato H. Agerelated valvular regurgitation: a study by pulsed Doppler echocardiography. Circulation 1987;76:262-5. 